\title{
Comparison of Quality of Life Scores in Patients Who Underwent Low Anterior Resection and Abdominoperineal Resection for Tumors of The Rectum
}

\author{
Mehmer İlker Turan ${ }^{1 *}$, Direnç Yiğit ${ }^{2}$, Mehmet Akif Türkoğlư ${ }^{3}$, Güner Öğünç ${ }^{1}$, Özgür Cem \\ Müsri $^{4}$, Umut Rıza Gündüz ${ }^{5}$, Bülent Dinç ${ }^{5}$ and Okan Erdoğan ${ }^{6}$ \\ ${ }^{1}$ Akdeniz University, Department of General Surgery, Turkey \\ ${ }^{2}$ Abbant İzzet Baysal University, Department of General Surgery, Turkey \\ ${ }^{3}$ Gazi University, Department of General Surgery, Turkey \\ ${ }^{4}$ Erzurum Regional Training and Research Hospital, Clinic of General Surgery, Turkey \\ ${ }^{5}$ Antalya Training and Research Hospital, Clinic of General Surgery, Turkey \\ ${ }^{6}$ Medstar Antalya Hospital, Clinic of General Surgery, Turkey \\ *Corresponding author: Mehmet İlker Turan, Akdeniz University, School of Medicine, Department of General Surgery, 07070, \\ Antalya, Turkey
}

\section{ARTICLE INFO}

Received: 幽 August 16, 2019

Published: 幽 August 26, 2019

Citation: Mehmer İlker T, Direnç Y, Mehmet Akif T, Güner Öğünç, Özgür Cem M, et al., Comparison of Quality of Life Scores in Patients Who Underwent Low Anterior Resection and Abdominoperineal Resection for Tumors of The Rectum. Biomed J Sci \& Tech Res 20(5)-2019. BJSTR. MS.ID.003516.

Keywords: Rectal Cancer; Surgery; Complications; Quality of Life; Short Form-36

\section{ABSTRACT}

Objectives: This study makes a comparison of the quality of life of patients who have undergone different forms of radical surgery for tumors of the rectum.

Background: Colorectal carcinoma is the third most common form of cancer among all cancer types, and the most common type of all gastrointestinal system cancers.

Methods: Patients who had undergone a Low Anterior Resection (LAR) or an Abdominoperineal Resection (APR) for rectal cancer were compared using the Short Form-36 (SF-36) quality of life measure.

Results: The physical function, role limitations due to physical functions, role limitations due to emotional problems, vitality, mental health, social functionality, and general health perception of the patients who underwent APR were statistically and significantly better then in patients who underwent LAR, while no significant difference was found in the bodily pain scores of the two groups.

Conclusion: Patients who underwent LAR achieve a quite good quality of life when no complications developed, while their quality of life was poorer than those fitted with a permanent stoma upon the development of complications. In this regard, the APR resection technique may be preferable to restorative procedures when there is a high risk of such complications as anastomotic stricture and anastomotic leakage.

\section{Introduction}

Colorectal carcinoma is one of the most common cancer [1]. Annually, approximately 1.4 million new cases are diagnosed, while 50,000 deaths occur due to colorectal cancers in the United States [2]. One third of all colorectal cancers are rectal cancers. The available surgical treatments for rectal cancer include, Low
Anterior Resection (LAR), Abdominoperineal Resection (APR), local excision and trans-anal endoscopic microsurgery. In the majority of patients, these surgical treatment methods result in serious transient or permanent complications, such as urinary incontinence, defecation problems and sexual dysfunction, and 
complications related to stoma, anal incontinence and strictures, respectively, that affect quality of life.

The success in cancer treatment is currently assessed on an evaluation of quality of life of the individual during and after the treatment course, in addition to the margin status of the resection or the survival of the patient [3]. On the other hand, patients have some emotional and disease burden difficulties followed by surgery. Quality of life not only depends on the disease diagnosis, but also postoperative short or long term are critical to restore the emotional disturbance of the patients. Some complications followed by surgery might differ among different surgical techniques and lead to additional disease burden for the patients. Up to now, there are conflicting results regarding comparisons of quality of life in patients undergoing permanent stoma and sphincter preserving anastomosis and anastomosis close to the anal canal. In this study, we aimed to compare the postoperative quality of life in patients who underwent LAR or APR due to rectal tumors.

\section{Materials and Methods}

\section{Study Design}

Data (surgery records and pathology data) of 369 patients who had undergone LAR or APR for rectal cancer at the University of Akdeniz, School of Medicine Hospital between May 2009 and December 2015 were analyzed retrospectively in the study. The patients were grouped further based on the applied surgical technique, such as laparoscopic LAR, conventional LAR, robotic LAR, laparoscopic APR and conventional APR. Patients with no follow-up, those who underwent operation due to benign tumors and those under the age of 18 years were excluded from the study. The procedure to be performed for the radical resection, such as APR or LAR, was determined based on the potential positivity of the distal and circumferential resection, stage of the tumor, joint decision of the surgeon and the patient during the preoperative phase, and intraoperative findings.
Demographics, type of operation, duration of follow-up, TNM stages, postoperative major complications (such as anastomotic stricture and anastomotic leakage), presence of a stoma, recurrence, status of metastasis and the result of the SF-36 quality of life measure applied following the surgical procedure of the patients included in the study were recorded. The SF-36 quality of life measure was used since it allows self-evaluation, can be performed in a short time and is able to evaluate both the positive and negative aspects of the health condition [4]. The measure is composed of 36 items that are grouped to allow the evaluation of eight different dimensions. The items on the measure evaluate such parameters as Physical Function (PF) (10 items), role limitations due to Physical Functions (RP) (4 items), role limitations due to Emotional Problems (RE) (3 items), Vitality (VT) (4 items), Mental Health (MH) (5 items), Social Function (SF) (2 items), and Bodily Pain (BP) (2 items), in addition to General Health Perception (GH) (5 items) [5]. The measure is scored between 0 and 100 for each parameter, rather than providing a single total point as a result. A score of zero in the evaluation of the results indicates poor health, while a 100-point score points to good health status [6].

The study was approved by the Clinical Trials Ethics Board of the Medical School of the University of Akdeniz and a Certificate of Approval was granted by the Clinical Trials Ethics Board with document number of 70904504/509 and decision number of 571 .

\section{Statistical Analysis}

The statistical evaluation of the obtained data was carried out using the SPSS v20 (IBM) package program. The demographics and clinical properties of the patients were expressed as mean \pm Standard Deviation (SD), median or percentages. Parametric data was analyzed using a Student's t-test, and non-parametric data was evaluated using Mann-Whitney $U$ and $\chi 2$ tests. A p value of $<0.05$ was considered statistically significant.

\section{Results}

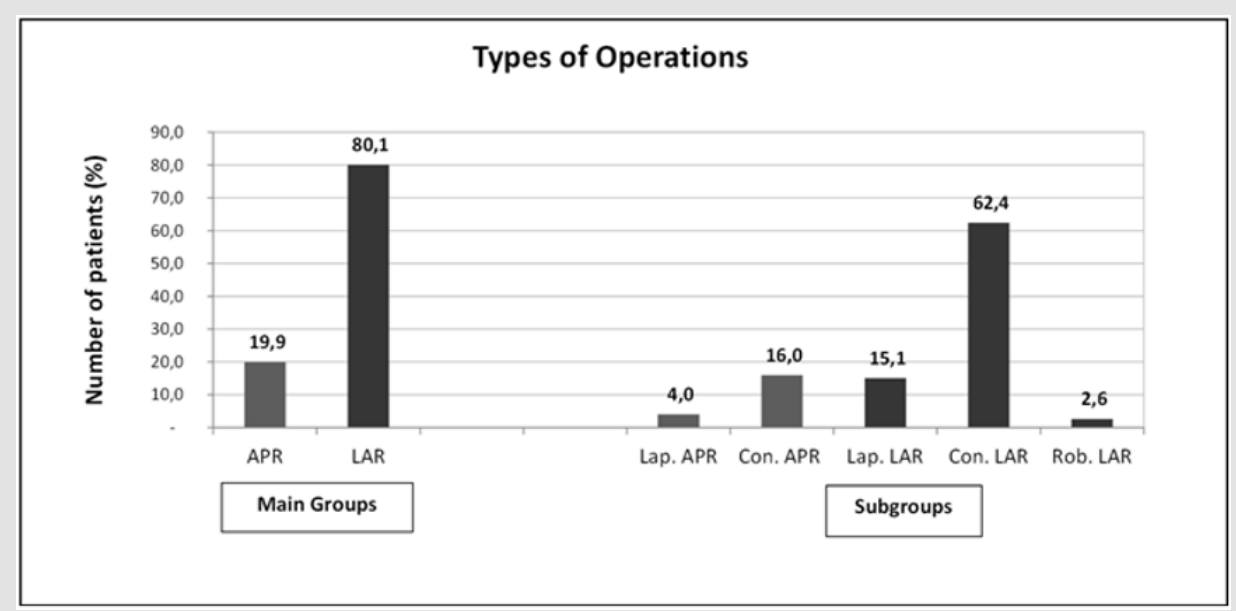

Note: APR: Abdominoperineal Resection, LAR: Low Anterior Resection, Lap: Laparoscopic, Con: Conservative, Rob: Robotic

Figure 1: Types of Operations. 
A total of 18 patients among the 369 patients were excluded from the study, seven due to no follow-up and 11 due to the presence of surgery secondary to benign reasons. The mean age was $60.91 \pm 12.3$ years and $62.41 \pm 11.8$ years in the patients who underwent APR and LAR, respectively. Among the patients who underwent APR, 31.4\% (n=22) were female and $68.6 \%$ $(n=48)$ were male, while $30.6 \%(n=86)$ and $69.4 \%(n=195)$ of the patients who underwent LAR were female and male, respectively. No demographic differences were noted between the main and subgroups. Among the 351 patients included in the study, 19.9\% $(\mathrm{n}=70)$ and $80.1 \%(\mathrm{n}=281)$ underwent APR and LAR, respectively. Among the patients in the APR group, 4\% (n=14) and 16\% (n=56) had undergone laparoscopic and conventional APR, respectively, while among the patients who underwent LAR, 62.4\% ( $\mathrm{n}=219)$, $15.1 \%(n=53)$ and $2.6 \%(n=9)$ had undergone conventional, laparoscopic and robotic LAR, respectively (Figure 1).

Table 1: Comparison of operation types according to TNM staging system.

\begin{tabular}{|c|c|c|c|c|c|c|c|c|}
\hline \multicolumn{4}{|c|}{ TNM Staging System } & \multicolumn{5}{|c|}{ Types of Operations } \\
\hline \multicolumn{4}{|c|}{$\begin{array}{c}\text { Main Groups } \\
\text { n(\%) }\end{array}$} & \multicolumn{5}{|c|}{$\begin{array}{l}\text { Subgroups } \\
\text { n(\%) }\end{array}$} \\
\hline \multicolumn{3}{|c|}{ APR } & LAR & Con. APR & $\begin{array}{l}\text { Lap. } \\
\text { APR }\end{array}$ & $\begin{array}{l}\text { Con. } \\
\text { LAR }\end{array}$ & $\begin{array}{l}\text { Lap. } \\
\text { LAR }\end{array}$ & $\begin{array}{l}\text { Rob. } \\
\text { LAR }\end{array}$ \\
\hline \multicolumn{2}{|c|}{ Stage -0} & $6(8.6 \%)$ & $21(21.5 \%)$ & $3(5.4 \%)$ & $3(21.4 \%)$ & $14(6.4 \%)$ & $5(9.4 \%)$ & $2(22.2 \%)$ \\
\hline \multicolumn{2}{|c|}{ Stage - 1} & $8(11.4 \%)$ & $31(11 \%)$ & $4(7.1 \%)$ & $4(28.6 \%)$ & $21(9.6 \%)$ & $10(18.9 \%)$ & $0(0 \%)$ \\
\hline \multirow[t]{2}{*}{ Stage - 2} & A & $22(31.4 \%)$ & $77(27.4 \%)$ & $17(30.4 \%)$ & $5(35.7 \%)$ & $61(27.9 \%)$ & $14(26.4 \%)$ & $2(22.2 \%)$ \\
\hline & B & $3(4.3 \%)$ & $10(3.6 \%)$ & $3(5.4 \%)$ & $0(0 \%)$ & $8(3.7 \%)$ & $1(1.9 \%)$ & $1(11.1 \%)$ \\
\hline \multirow[t]{3}{*}{ Stage - 3} & $\mathrm{~A}$ & $0(0 \%)$ & $8(2.8 \%)$ & $0(0 \%)$ & $0(0 \%)$ & $5(2.3 \%)$ & $1(1.9 \%)$ & $2(22.2 \%)$ \\
\hline & B & $12(17.1 \%)$ & $77(27.4 \%)$ & $12(21.4 \%)$ & $0(0 \%)$ & $62(28.3 \%)$ & $13(24.5 \%)$ & $2(22.2 \%)$ \\
\hline & $\mathrm{C}$ & $16(22.9 \%)$ & $46(16.4 \%)$ & $14(25 \%)$ & $2(14.3 \%)$ & $37(16.9 \%)$ & $9(17 \%)$ & $0(0 \%)$ \\
\hline \multirow[t]{2}{*}{ Stage -4} & $\mathrm{~A}$ & $2(2.9 \%)$ & $7(2.5 \%)$ & $2(3.6 \%)$ & $0(0 \%$ & $7(3.2 \%)$ & $0(0 \%)$ & $0(0 \%)$ \\
\hline & $\mathrm{B}$ & $1(1.4 \%)$ & $4(1.4 \%)$ & $1(1.8 \%)$ & $0(0 \%)$ & $4(1.8 \%)$ & $0(0 \%)$ & $0(0 \%)$ \\
\hline
\end{tabular}

Note: APR: Abdominoperineal Resection, LAR: Low Anterior Resection, Lap: Laparoscopic, Con: Conservative, Rob: Robotic

Major complications in postoperative period (stricture in the colon anastomosis, leakage in the colon/small bowel anastomosis) were seen in 36 (12.8\%) patients, all of which had undergone LAR. In the subgroups, major complications developed in 24 (11\%) out of the 219 patients who underwent conventional LAR, and in 12
The mean duration of follow-up of the patients evaluated in the study was $38 \pm 26$ months (0-94 months), while the mean duration of follow-up in the APR and LAR groups were 35 \pm 23 months (7-93 months) and 39 \pm 26 months (0-94 months), respectively. The one-, three- and five-year overall survival rates were $90.4 \%, 68.2 \%$ and $60.4 \%$, respectively. No significant difference was found in survival durations of the patients who underwent APR and those who underwent LAR ( $\mathrm{p}=0.951)$.

The pathological staging of the patients is presented in Table 1. No statistically significant difference was observed in the stagings of the main APR and LAR groups ( $p=0.627)$. In a statistical analysis of the different operation subtypes, the pathological stage was found to be significantly lower in patients who underwent LAR when compared to the other types of operation $(p=0.030)$.

Table 2: Comparison of operation types according to TNM staging system.

\begin{tabular}{|c|c|c|c|c|c|c|c|}
\hline \multicolumn{8}{|c|}{ Types of Operations } \\
\hline \multicolumn{3}{|c|}{$\begin{array}{c}\text { Main Groups } \\
\text { n(\%) }\end{array}$} & \multicolumn{5}{|c|}{$\begin{array}{c}\text { Subgroups } \\
\text { n(\%) }\end{array}$} \\
\hline $\mathbf{n}$ & $\begin{array}{l}\text { APR } \\
-70\end{array}$ & $\begin{array}{l}\text { LAR } \\
-281\end{array}$ & $\begin{array}{c}\text { Con. } \\
\text { APR } \\
-56\end{array}$ & $\begin{array}{c}\text { Lap. } \\
\text { APR } \\
-14\end{array}$ & $\begin{array}{l}\text { Con. } \\
\text { LAR } \\
-219\end{array}$ & $\begin{array}{l}\text { Lap. } \\
\text { LAR } \\
-53\end{array}$ & $\begin{array}{c}\text { Rob. } \\
\text { LAR } \\
-9\end{array}$ \\
\hline Complications & - & $36(12.8 \%)$ & - & - & $24(11 \%)$ & $12(22.6 \%)$ & - \\
\hline - Anastomotic stenosis & - & $25(8.9 \%)$ & - & - & $15(6.8 \%)$ & $10(\% 18.9)$ & - \\
\hline - Colonic leakage & - & $9(3.2 \%)$ & - & - & $7(3.2 \%)$ & $2(3.8 \%)$ & - \\
\hline · Ileal leakage & - & $2(0.7 \%)$ & - & - & $2(0.9 \%)$ & - & - \\
\hline Local Recurrence & $7(10.3 \%)$ & $25(8.9 \%)$ & $4(7.1 \%)$ & $3(25 \%)$ & $22(10 \%)$ & $3(5.7 \%)$ & - \\
\hline Distant Metastases & $10(20.8 \%)$ & $24(12.7 \%)$ & $7(20 \%)$ & $3(21.4 \%)$ & $20(15 \%)$ & $4(9.5 \%)$ & - \\
\hline
\end{tabular}

Note: APR: Abdominoperineal Resection, LAR: Low Anterior Resection, Lap: Laparoscopic, Con: Conservative, Rob: Robotic 
Local recurrence was seen in $9.2 \%(n=32)$ of all patients. When the main groups were analyzed, seven out of $70(10.3 \%)$ in the APR group, and 25 out of 281 (8.9\%) in the LAR group had a local recurrence. No statistically significant difference was found between the groups $(\mathrm{p}=0.815)$. Among the subgroups, a local recurrence developed in $7.1 \%(n=4), 25 \%(n=3), 10 \%(n=22)$ and $5.7 \%(n=3)$ of the patients who underwent conventional APR, laparoscopic APR, conventional LAR and laparoscopic LAR, respectively, while no local recurrence was noted in patients who underwent a robotic LAR (Table 2).

Among all patients $14.3 \%(n=34)$ developed metastatic disease, and among the main groups, $20.8 \%(n=10)$ and $12.7 \%(n=24)$ of the patients who underwent APR and LAR, respectively, developed metastatic disease, with no statistically significant difference found between the groups ( $p=0.170)$. When the subgroups were analyzed, metastatic disease developed during the follow-up in $20 \%(n=7)$, $21.4 \%(n=3), 15 \%(n=20)$ and $9.5 \%(n=4)$ of the patients who underwent conventional APR, laparoscopic APR, conventional LAR and laparoscopic LAR, respectively, while no metastatic disease developed in patients who underwent robotic LAR.

The overall mortality rate was found to be $31.9 \%(n=112)$. Among the main groups, the mortality rate was $29.4 \%(\mathrm{n}=20)$ and $32.7 \%(n=92)$ in the APR and LAR groups, respectively ( $p=0.665)$. When the subgroups were analyzed, the mortality rate was found to be $35.7 \%(n=20), 37 \%(n=81)$ and $20.8 \%(n=11)$ in patients who underwent conventional APR, conventional LAR and laparoscopic LAR, respectively, while no mortality was found in the laparoscopic APR or robotic LAR groups. When the patients who underwent laparoscopic and conventional LAR were compared, mortality was found to be lower in the laparoscopic LAR group ( $\mathrm{p}=0.035)$. No statistical evaluation could be made of patients who underwent a

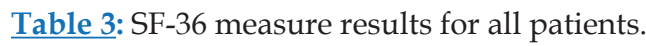

robotic LAR, since no adequate duration of follow-up was reached. Although surgical mortality (mortality developing in the first 30 days postoperatively) occurred in $1.4 \%(n=5)$ of the patients, all of those with surgical mortality were found to be in the conventional LAR group. No subgroup analysis could be made for surgical mortality due to the inadequate sample size.

The results of the SF-36 quality of life measure applied to patients in the study in the postoperative period were analyzed for the main groups (LAR and APR), independent of the rate of development of complications and the sub-groups (conventional APR, laparoscopic APR, conventional LAR, laparoscopic LAR and robotic LAR). The mean values in the measure in the Physical Function (PF), role limitations due to physical functions (RP), role limitations due to Emotional Problems (RE), Vitality (VT), Mental Health (MH), Social Function (SF), Bodily Pain (BP), and General Health perception $(\mathrm{GH})$ parameters are presented in Table 3. The overall results of the SF36 quality of life measure independent of all the groupings were calculated as $61.4 \pm 19.5$ for $\mathrm{PF}, 61.6 \pm 16.3$ for RP, $66.3 \pm 23.7$ for RE, $61.6 \pm 21.7$ for VT, $63.6 \pm 20.9$ for $\mathrm{MH}, 64.0 \pm 18.0$ for $\mathrm{SF}, 66.3 \pm 12.3$ for $\mathrm{BP}$ and $62.4 \pm 18.9$ for $\mathrm{GH}$. The physical function, RP, RE, VT, MH, SF and GH scores were found to be higher in patients who underwent APR than in those who underwent LAR, and quality of life was statistically significantly better in the patients who underwent APR ( $\mathrm{p}=0.001)$. No statistically significant difference was found in parameter BP between the patients who underwent APR and LAR ( $\mathrm{p}=0.856)$. The highest score from the SF36 was achieved by patients who underwent robotic LAR, followed by, in descending order, those who underwent laparoscopic APR, conventional APR, laparoscopic LAR and conventional LAR, when the overall SF-36 measure results of the patients were evaluated, independent of the development of complications ( $\mathrm{p}=0.001)$ (Table $3)$.

\begin{tabular}{|c|c|c|c|c|c|c|c|c|}
\hline \multicolumn{9}{|c|}{ Types of Operations } \\
\hline & \multicolumn{5}{|c|}{$\begin{array}{c}\text { Main Groups } \\
\text { (Mean } \pm \text { SD) }\end{array}$} & \multicolumn{3}{|c|}{$\begin{array}{l}\text { Subgroups } \\
\text { (Mean } \pm \text { SD) }\end{array}$} \\
\hline & APR & LAR & $\mathbf{p}$ & $\begin{array}{l}\text { Con. } \\
\text { APR }\end{array}$ & $\begin{array}{l}\text { Lap. } \\
\text { APR }\end{array}$ & $\begin{array}{l}\text { Con. } \\
\text { LAR }\end{array}$ & $\begin{array}{l}\text { Lap. } \\
\text { LAR }\end{array}$ & $\begin{array}{l}\text { Rob. } \\
\text { LAR }\end{array}$ \\
\hline Physical Function(PF) & $69.6 \pm 12.6$ & $59.3 \pm 20.4$ & 0.001 & $69.1 \pm 12.8$ & $71.0 \pm 12.4$ & $57.4 \pm 19.3$ & $60.4 \pm 12.6$ & $82.3 \pm 6.7$ \\
\hline Role- Physical(RP) & $67.5 \pm 12.5$ & $60.1 \pm 16.9$ & 0.01 & $66.0 \pm 13.0$ & $71.4 \pm 10.6$ & $58.3 \pm 16.7$ & $60.8 \pm 15.7$ & $83.2 \pm 6.8$ \\
\hline Role-Emotional(RE) & $72.6 \pm 14.5$ & $68.4 \pm 25.0$ & 0.03 & $71.2 \pm 15.3$ & $76.4 \pm 11.4$ & $31.0 \pm 24.8$ & $71.3 \pm 23.7$ & $88.8 \pm 5.9$ \\
\hline Vitality(VT) & $69.2 \pm 10.0$ & $59.7 \pm 23.3$ & 0.001 & $66.7 \pm 10.6$ & $76.2 \pm 7.6$ & $57.6 \pm 21.8$ & $61.4 \pm 28.2$ & $80.1 \pm 6.7$ \\
\hline Mental Health(MH) & $68.4 \pm 10.3$ & $62.9 \pm 22.8$ & 0.02 & $67.1 \pm 11.2$ & $71.8 \pm 6.6$ & $63.0 \pm 22.3$ & $58.0 \pm 24.9$ & $80.4 \pm 7.0$ \\
\hline Social Function(SF) & $68.7 \pm 11.0$ & $62.2 \pm 18.9$ & 0.01 & $67.1 \pm 11.5$ & $73.1 \pm 8.6$ & $60.9 \pm 17.2$ & $63.6 \pm 23.6$ & $87.5 \pm 4.6$ \\
\hline Bodily Pain(BP) & $66.2 \pm 12.3$ & $66.3 \pm 12.3$ & $N S$ & $64.9 \pm 12.5$ & $69.9 \pm 11.3$ & $65.0 \pm 11.1$ & $67.0 \pm 14.6$ & $82.4 \pm 7.1$ \\
\hline General Health(GH) & $69.4 \pm 13.0$ & $60.6 \pm 19.7$ & 0.001 & $67.0 \pm 13.6$ & $76.4 \pm 8.8$ & $60.0 \pm 19.1$ & $58.0 \pm 21.7$ & $79.9 \pm 6.9$ \\
\hline
\end{tabular}

Note: APR: Abdominoperineal Resection, LAR: Low Anterior Resection, Lap: Laparoscopic, Con: Conservative, Rob: Robotic

The parameters of $P F(p=0.294), R P(p=0.793), R E(p=0.533)$, VT $(p=0.280)$, BP $(p=0.979)$ and $G H(p=0.138)$ were similar in the patients in the LAR and APR groups, regardless of the development of complications. The results of the SF-36 measure in $\mathrm{MH}(\mathrm{p}=0.01)$ and SF ( $\mathrm{p}=0.004)$ were found to be statistically significantly higher in patients who underwent LAR without complications than in patients who underwent APR. When evaluated based on the applied surgical technique, the highest scores of quality of life for the 
parameters PF, RP, RE, VT, MH, SF and GH were achieved in the group of patients who underwent robotic LAR with no complications, followed by the groups of patients who underwent laparoscopic Table 4: SF-36 measure results for patients without complications.
LAR, laparoscopic APR, conventional LAR and conventional APR, in descending order (Table 4).

\begin{tabular}{|c|c|c|c|c|c|c|c|c|}
\hline \multicolumn{9}{|c|}{ Types of Operations } \\
\hline \multicolumn{3}{|c|}{$\begin{array}{c}\text { Main Groups } \\
\text { (Mean } \pm \text { SD) }\end{array}$} & \multicolumn{6}{|c|}{$\begin{array}{l}\text { Subgroups } \\
\text { (Mean } \pm \text { SD) }\end{array}$} \\
\hline & APR & LAR & $p$ & Con. APR & Lap. APR & Con. LAR & Lap. LAR & Rob. LAR \\
\hline Physical Function(PF) & $69.6 \pm 12.6$ & $67.1 \pm 14.9$ & NS & $69.1 \pm 12.8$ & $71.0 \pm 12.4$ & $63.2 \pm 14.7$ & $76.5 \pm 9.3$ & $82.3 \pm 6.7$ \\
\hline Role- Physical(RP) & $67.5 \pm 12.5$ & $66.8 \pm 14.3$ & NS & $66.0 \pm 13.0$ & $71.4 \pm 10.6$ & $64.4 \pm 14.3$ & $70.6 \pm 11.5$ & $83.2 \pm 6.8$ \\
\hline Role- Emotional(RE) & $72.6 \pm 14.5$ & $74.7 \pm 22.1$ & NS & $71.2 \pm 15.3$ & $76.4 \pm 11.4$ & $69.6 \pm 23.2$ & $88.5 \pm 10.1$ & $88.8 \pm 5.9$ \\
\hline Vitality(VT) & $69.2 \pm 10.7$ & $71.7 \pm 15.0$ & NS & $66.7 \pm 10.6$ & $76.0 \pm 7.6$ & $67.5 \pm 16.0$ & $82.9 \pm 5.5$ & $80.1 \pm 6.7$ \\
\hline Mental Health(MH) & $68.4 \pm 10.3$ & $74.3 \pm 14.7$ & 0.01 & $67.1 \pm 11.2$ & $71.8 \pm 6.6$ & $73.0 \pm 16.4$ & $75.8 \pm 10.5$ & $80.4 \pm 7.0$ \\
\hline Social Function(SF) & $68.7 \pm 11.0$ & $73.6 \pm 9.5$ & 0.004 & $67.1 \pm 11.2$ & $71.8 \pm 6.6$ & $73.0 \pm 16.4$ & $81.4 \pm 4.9$ & $87.5 \pm 4.6$ \\
\hline Bodily Pain(BP) & $66.2 \pm 12.3$ & $66.3 \pm 11.2$ & NS & $64.5 \pm 12.5$ & $69.9 \pm 11.3$ & $63.4 \pm 10.6$ & $72.0 \pm 7.1$ & $82.4 \pm 7.1$ \\
\hline General Health(GH) & $69.4 \pm 13.0$ & $71.9 \pm 8.7$ & NS & $67.0 \pm 13.6$ & $76.0 \pm 8.8$ & $70.3 \pm 9.4$ & $73.6 \pm 8.5$ & $79.9 \pm 6.9$ \\
\hline
\end{tabular}

Note: APR: Abdominoperineal Resection, LAR: Low Anterior Resection, Lap: Laparoscopic, Con: Conservative, Rob: Robotic

\section{Discussion}

When a radical resection is decided upon for a rectum tumor, the selection of the type of operation, whether APR or LAR, depends on the patient (gender and preoperative sphincter function), tumor (stage, potential distal resection margin) and the preference of the surgeon [7].

Advances in surgical techniques and medical procedures have resulted in an increase in five-year survival rates from around 50\% to $66 \%$ from 1975 to 2016 in rectal cancer [8,9]. Omidvari et al. [10] reported a five-year overall survival rate of $69.4 \%$ in a study of 153 patients diagnosed with rectal cancer, while Wibe et al. [11], in another study involving 2,136 patients with rectal cancer, recorded a five-year overall survival rate of $63 \%$, while five-year survival rates for APR and LAR were found to be $55 \%$ and $68 \%$, respectively. The overall five-year survival rate can be expected to be low in study groups with a high number of patients at late stages, since survival is directly associated with stage in rectal cancer. The overall fiveyear survival rate in the present study is relatively lower than those reported in the literature $(60.4 \%)$, and this is probably associated with the fact that the majority of our patients were at Stage 3-4 (49.4\%, n=173).

Complications associated with anastomosis following restorative rectal cancer operations may seriously affect the success of surgery. The most commonly seen anastomosis-related complications after LAR have been reported to be stenosis, leakage and bleeding [12]. The frequency of leakage in colonic anastomosis in the postoperative period following LAR has been reported to be between 2 and 36\%, at varying rates [13-16]. The frequency of leakage in the colonic anastomosis following laparoscopic LAR has been reported at rates varying between 3 and 19\%, while most reports record rates of between 10 and 13\% [17-21]. Kim et al. [22], compared conventional and laparoscopic techniques in terms of colonic anastomosis-related complications and found an anastomotic leakage rate of $7.3 \%$ and $5.8 \%$ in patients who underwent operations using the laparoscopic and conventional technique, respectively, with no statistically significant difference between the two groups in terms of the development of leakage. In a COLOR-II study in which laparoscopic and conventional surgery was compared in the surgical treatment of rectal cancer, the rate of anastomotic leaks was found to be $13 \%$ and $10 \%$ in patients who underwent a laparoscopic LAR and conventional LAR, respectively, with no statistically significant difference identified between the two groups [23]. In a study by Pucciarelli et al. [24], endoscopically diagnosed anastomotic strictures with symptomatic stenosis were reported to be associated with preoperative radiotherapy, local recurrence and anastomotic leakage. In addition, anastomotic leaks were reported to cause such complications as the development of local recurrence and anastomotic stricture in various case series and meta-analysis studies in literature $[25,26]$. The colonic anastomotic leak rate was recorded as $3.2 \%$ in the present study, while this rate was $3.8 \%$ and $3.2 \%$ in patients who had undergone conventional and laparoscopic techniques, respectively, with no statistically significant difference recorded between the two techniques in terms of leak rates.

The other complication associated with colonic anastomosis in patients undergoing LAR is anastomotic stricture, which is seen in up to $30 \%$ of patients $[27,28]$, while this rate has been reported to be $2-10 \%$ and $1.3-11.8 \%$ in laparoscopic and conventionally performed cases, respectively $[27,29]$. No statistically significant difference was reported in the development of anastomotic stricture between the two techniques in a study by Pecorelli et al. [30] detailing the long-term outcome of patients following laparoscopic and conventional operations, and Kellokumpu et al. [29] reported similar results to Pecorelli et al. in their study comparing laparoscopic and conventional techniques. The rate of 
development of anastomotic stricture was $18.8 \%$ and $6.8 \%$ in the present study in patients undergoing laparoscopic and conventional LAR, respectively, and the rate was statistically significantly higher in the laparoscopic LAR group ( $p=0.014)$. The possible risk factors associated with anastomotic stricture reported in the literature have been tension in the anastomotic line, ischemia, high ligation of the inferior mesenteric artery and fecal diversion [31]. It was unknown in the present study that why the anastomotic stricture rate was higher in patients who had undergone laparoscopic LAR, since those risk factors were not analyzed within the scope of the study.

The rate of local recurrence following LAP and APR for rectal cancer has been reported in the literature to be $10-18 \%$ and $15-$ $28 \%$, respectively; however, there are contradictory results about which type of operation (APR or LAR) is superior in terms of local recurrence rates $[27,32]$. Some authors have reported higher local recurrence rates after APR [11,33], while others have reported the opposite [34]. In the present study, the local recurrence rate was found to be $8.9 \%$ and $10.3 \%$ in patients undergoing LAR and APR, respectively, with no statistically significant difference between the groups. These findings are compatible with the literature. Recurrence rates were reported to be $3.9 \%$ and $5.5 \%$ in laparoscopic and conventional operations, with no statistically significant difference between the groups in a study evaluating the development of recurrence rates, regardless of LAR or APR, but depending on laparoscopic and conventional techniques [35].

Recurrence rates were reported to be $8.7 \%$ and $10.8 \%$ for conventional and laparoscopic operations, respectively in another study, and local recurrence was reported to be lower following conventional surgery [36]. Nevertheless, general opinion is that no difference exists between the laparoscopic and conventional techniques, regardless of LAR or APR, although situations that might lead to morbidity, such as duration of operation, intraoperative bleeding, and the requirement for blood and blood products are different between the procedures $[37,38]$. In this present study, the rates of development of local recurrences with laparoscopic APR and laparoscopic LAR and conventional APR and conventional LAR were found to be compatible with findings in literature. These rates were $9.89 \%$ and $9.45 \%$ for laparoscopic and conventional techniques, respectively, with no statistically significant difference in the local recurrence between the laparoscopic and conventional techniques in terms of long-term follow-up. No reliable statistical evaluation could be made of patients who underwent robotic LAR due to the inadequate duration of follow-up and the fewer patients in this group than in other groups.

Controversial results have been reported related to the development of metastasis following APR and LAR procedures for rectal cancer. Some studies report no difference between APR and LAR in terms of metastasis rates [39-41], while other studies have reported statistically significantly lower rates of metastasis development in patients who underwent LAR $[33,42,43]$. The rate of development of metastasis following surgery for rectal cancer has been reported in the range of $17-38 \%$ and $14-34 \%$ for APR and LAR, respectively, in literature $[40,41,44]$. In this present study, the rate of distant (systemic) metastasis was found to be $20.8 \%$ and $12.7 \%$ for the APR and LAR groups, respectively, with no statistically significant difference between the groups. No reliable statistical evaluation could be made of patients who underwent robotic LAR due to the inadequate duration of follow-up and the fewer number of patients when compared to other groups.

Many studies and meta-analyses have been carried out evaluating the quality of life of patients who underwent LAR and APR, making use of various evaluation measures. In a study by Digennaro et al. [45] involving 50 patients using CR38, C30 and SF36, the quality of life of patients who underwent LAR and APR was found to be similar, aside from in sexual function. Patients were found to psychologically improve, independent of the permanent stoma status, based on the SF-36 measure, and the quality of life scores were found to be negatively affected by obstruction or incontinence following LAR [45]. A picture defined as low anterior resection syndrome, characterized by fecal incontinence, sensation of urgency to defecate, incomplete defecation, sensation of incomplete evacuation following defecation and increased bowel motility has been observed in $25-80 \%$ of patients who underwent LAR. Low anterior resection syndrome largely affects the quality of life of the patients, such that some prefer the permanent colostomy option in a bid to overcome the symptoms $[46,47]$. Based on the findings of the application of the C30 and CR38 scales, no difference was found in the general health perception of patients who had undergone ALR or APR in a study by How et al. [48] involving 62 patients with LAR or APR, although social and cognitive functions were observed to be better in patients who had undergone APR. The general health perception, and physical, emotional and social function were similar in patients who had undergone APR and LAR in a study by Dumont et al. [49], although problems with defecation occurring in patients who had undergone LAR, such as fecal incontinence, were reported to affect quality of life scores quite negatively.

Physical function was found to be similar in patients who had undergone APR and LAR in a study by Grumann et al. [50], although patients with APR had statistically significantly higher quality of life scores in terms of emotional function, social function and futurity perception. In a Cochrane systematic analysis published in 2012 [51] evaluating the effect of a permanent stoma on quality of life in patients who underwent surgery for rectal cancer, quality of life was found to be no lower in patients with a permanent stoma than in patients with no permanent stoma. Furthermore, no difference in the quality of life was found between patients who underwent APR and LAR [50,52-54]. On the other hand, patients who underwent LAR achieved superior quality of life scores when compared to patients with APR in only some of the parameters included in the applied measures [55-57]; patients who underwent LAR were found to have better quality of life scores than those with LAR 
[58,59] and one study demonstrated that patients with APR had statistically significantly higher quality of life scores than patients with LAR [60].

In a meta-analysis by Cornish et al. [7], 11 studies using the SF36, CR38 or C30 scales were evaluated, and no difference was found in the general health perception of the patients who underwent APR and LAR, although those with LAR were found to have higher quality of life scores in physical functions, where patients with APR had higher quality of life scores in emotional and cognitive functions. In a meta-analysis by Maslyankov et al. [61], 13 studies using the C30 or CR38 scales were analyzed, and no significant differences were found in the general health perception, physical function, emotional function and futurity perception of patients who had undergone APR and with LAR, while the quality of life measure points related to social function and body appearance were found to be significantly higher in patients who had LAR compared to those who had APR.

In the present study, on the other hand, the quality of life evaluation measure scores in patients who underwent APR were significantly higher in the physical function, emotional role difficulty, physical role difficulty, mental health, social functioning and general health perception parameters than in patients who underwent LAR in an evaluation carried out disregarding the postoperative complication status of the patients; however no difference was found in the pain parameters of the two groups. Confirming the hypothesis "the development of complications has a negative effect on the quality of life measure scores of patients who underwent LAR", the difference that was once present was found to have disappeared in the physical function, physical role difficulty, emotional role difficulty, energy-stamina-vitality and general health perception parameters when the analysis was carried out including patients who underwent LAR with no complications and those who underwent APR. That said, the mental health and social functioning parameters were observed to become statistically significantly higher in patients who underwent LAR without complications when compared to patients with APR.

When the quality of life measure scores obtained in the present study were compared with the Turkish society mean SF36-measure scores published by Demiral et al. [62], the quality of life measure scores in patients who underwent robotic LAR were found to be almost equal to the normal values obtained in Turkish society and patients who underwent laparoscopic LAR with no complications followed those patients. The mean perception of general health in Turkish society has been demonstrated to be $71.6 \pm 16.1$, while the general health perception scores in patients who underwent robotic LAR, laparoscopic LAR and laparoscopic APR in this present study were found to be almost equal to the mean SF-36 quality of life measure scores of the healthy Turkish population.

Among the patients who underwent a robotic LAR, five-year survival rates were reported at rates varying between 73 and $81 \%$ in literature $[63,64]$, and no statistically significant difference has been identified between patients who were operated on using laparoscopic and robotic techniques in long-term survival $[65,66]$. The five-year local recurrence rate in patients undergoing robotic LAR have been reported to be about 2.3-5.9\%, and no difference has been identified between the robotic and laparoscopic procedures in this regard, although robotic surgery has been found to be superior to conventional surgery $[65,66]$. No reliable statistical evaluation was performed in the present study in patients undergoing robotic LAR, since only nine patients underwent such a procedure, the operations were performed at a later time period compared to other operation types, and patients with robotic LAR had shorter duration of follow-up, although we observed that patients who underwent a robotic LAR scored better in the recurrence, metastasis, mortality and development of complications parameters. We believe that more reliable evaluations may be made with a larger number of cases, and with a five-year follow-up.

No objective evaluation of postoperative changes could be made in the present study, since no quality of life evaluations were made in the preoperative period. A preoperative evaluation of the SF-36 quality of life measure after the diagnosis of rectal cancer, and after postoperative early and long-term evaluations, would allow a more objective evaluation of changes in quality of life.

The continuation of the intestinal passage in the treatment of rectal cancer is desired in every patient; however, the primary aim in the treatment of rectal cancer should be in line with oncological principles, and sphincter preserving surgery should be a secondary aim in this regard. Since no difference was found in the oncological outcome of patients who underwent APR and LAR, and that APR was found to be superior in terms of quality of life in the present study, the risk of development of complications should be evaluated carefully both pre- and intra operatively. It was concluded that patients who underwent LAR have a quite good quality of life when no complications develop, while their quality of life was poorer than that of patients with a permanent stoma when complications developed. In this regard, the preferred resection technique may be APR rather than restorative procedures when there is a high risk of complications, such as anastomotic stricture and anastomotic leakage.

\section{Conflict of interest}

The authors declare that there is no conflict of interest.

\section{References}

1. Boyle P, Ferlay J (2005) Cancer incidence and mortality in Europe, 2004. Ann Oncol 16(3): 481-488.

2. (2018) Society AC. Cancer facts and figures 2018

3. Dunn J, Lynch B, Aitken J, Leggett B, Pakenham K, et al. (2003) Quality of life and colorectal cancer: A review. Aust N Z J Public Health 27(1): 41-53.

4. Ware JE, Sherbourne CD (1992) The MOS 36-item short-form health status survey (SF-36), I: Conceptual framework and item selection. Med Care 30(6): 473-483. 
5. Ware J, Snow K, Kosinski M, Gandek B (1992) SF-36 health survey manual and interpretation guide. Bost New Engl Med Cent 30(6): 473483.

6. Carr AJ, Thompson PW KJ (1996) Quality of life measures. Br J Rheumatol 35(3): 275-281.

7. Cornish JA, Tilney HS, Heriot AG, Lavery IC, Fazio VW, et al. (2007) A meta-analysis of quality of life for abdominoperineal excision of rectum versus anterior resection for rectal cancer. Ann Surg Oncol 14(7): 20562068.

8. Howlader N (2012) SEER Cancer statistics review 1975-2010. J Nat Cancer Inst.

9. (2014) Society AC. Colorectal Cancer Facts \& Figures 2014-2016. Color Cancer Facts.

10. Omidvari S, Hamedi SH, Mohammadianpanah M, Razzaghi S, Mosalaei A et al. (2013) Comparison of abdominoperineal resection and low anterior resection in lower and middle rectal cancer. J Egypt Natl Canc Inst 25(3): 151-160.

11. Wibe A, Syse A, Andersen E, Tretli S, Myrvold HE, et al. (2004) Oncological outcomes after total mesorectal excision for cure for cancer of the lower rectum: Anterior vs. Abdominoperineal Resection. Dis Colon Rectum 47(1): 48-58

12. Raskin E MR (2015) Complications of rectal cancer surgery. In: Walter E Longo, Vikram Reddy, Riccardo A Audisio (Eds). Modern management of cancer of the rectum. London: Springer, 447-459.

13. Mongin C, Maggiori L, Agostini J, Ferron M, Panis Y (2014) Does anastomotic leakage impair functional results and quality of life after laparoscopic sphincter-saving total mesorectal excision for rectal cancer? A case-matched study. Int J Colorectal Dis 29(4): 459- 467.

14. Park J, Neuman HB, Bennett AV, Polskin L, Phang PT, et al. (2014) Patient expectations of functional outcomes after rectal cancer surgery: A qualitative study. Dis Colon Rectum 57(2): 151-157.

15. Marinatou A, Theodoropoulos GE, Karanika S, Karantanos T, Siakavellas S, et al. (2014) Do anastomotic leaks impair postoperative health-related quality of life after rectal cancer surgery? A case-matched study. Dis Colon Rectum 57(2): 159-166.

16. Paun BC, Cassie S, MacLean AR, Dixon E, Buie WD (2010) Postoperative complications following surgery for rectal cancer. Ann Surg 251(5): 807 818.

17. Matsubara N, Miyata H, Gotoh M, Tomita N, Baba H, et al. (2014) Mortality after common rectal surgery in Japan: A study on low anterior resection from a newly established nationwide large-scale clinical database. Dis Colon Rectum 57(9): 1075-1081.

18. Shiomi A, Ito M, Maeda K, Kinugasa Y, Ota M, et al. (2015) Effects of a diverting stoma on symptomatic anastomotic leakage after low anterior resection for rectal cancer: A propensity score matching analysis of 1,014 consecutive patients. J Am Coll Surg 220(2): 186-194.

19. Qu H, Liu Y, Song BD (2015) Clinical risk factors for anastomotic leakage after laparoscopic anterior resection for rectal cancer: A systematic review and meta-analysis. Surg Endosc 29(12): 3608-3617.

20. Kang CY, Halabi WJ, Chaudhry 00, Nguyen V, Pigazzi A, et al. (2013) Risk factors for anastomotic leakage after anterior resection for rectal cancer. JAMA Surg 148(1): 65-71.

21. Kingham TP, Pachter HL (2009) Colonic anastomotic leak: Risk factors, diagnosis, and treatment. J Am Coll Surg 208(2): 269-278.

22. Kim CW, Baek SJ, Hur H, Min BS, Baik SH, et al. (2016) Anastomotic leakage after low anterior resection for rectal cancer is different between minimally invasive surgery and open surgery. Ann Surg 263(1): 130-137.

23. van der Pas MH, Haglind E, Cuesta MA, Fürst A, Lacy AM, et al. (2013) Laparoscopic versus open surgery for rectal cancer (COLOR II): Shortterm outcomes of a randomised, phase 3 trial. Lancet Oncol 14(3): 210218.
24. Pucciarelli S, Toppan P, Pilati PL, Piccoli A, Chemello F, et al. (1994) Efficacy of dilatations for anastomotic colorectal stenoses: Prognostic factors. Int J Colorectal Dis 9(3): 149-152.

25. Wang S, Liu J, Wang S, Zhao H, Ge S, et al. (2017) Adverse effects of anastomotic leakage on local recurrence and survival after curative anterior resection for rectal19 cancer: A systematic review and metaanalysis. World Journal of Surgery 41(1): 277-284.

26. Kulu Y, Tarantio I, Warschkow R, Kny S, Schneider M, et al. (2015) Anastomotic leakage is associated with impaired overall and diseasefree survival after curative rectal cancer resection: A propensity score analysis. Ann Surg Oncol 22(6): 2059-2067.

27. Park EJ, Baik SH, Kang J, Hur H, Min BS, et al. (2016) The impact of postoperative complications on long-term oncologic outcomes after laparoscopic low anterior resection for rectal cancer. Med (Baltimore) 95(14): e3271.

28. Bannura GC, Cumsille MA, Barrera AE, Contreras JP, Melo CL, et al. (2004) Predictive factors of stenosis after stapled colorectal anastomosis: Prospective analysis of 179 consecutive patients. World J Surg 28(9): 921-925.

29. Kellokumpu IH, Kairaluoma MI, Nuorva KP, Kautiainen HJ, Jantunen IT (2012) Short - and long-term outcome following laparoscopic versus open resection for carcinoma of the rectum in the multimodal setting. Dis Colon Rectum 55(8): 854-863.

30. Pecorelli N, Amodeo S, Frasson M, Vignali A, Zuliani W, et al. (2016) Tenyear outcomes following laparoscopic colorectal resection: Results of a randomized controlled trial. International Journal of Colorectal Disease 31(7): 1283-1290.

31. Hayden DM, Mora Pinzon MC, Francescatti AB, Saclarides TJ (2015) Patient factors may predict anastomotic complications after rectal cancer surgery: Anastomotic complications in rectal cancer. Ann Med Surg 4(1): 11-16.

32. Kim JC, Yu CS, Lim SB, Kim CW, Kim JH, et al. (2013) Abdominoperineal resection and low anterior resection: Comparison of long-term oncologic outcome in matched patients with lower rectal cancer. Int J Colorectal Dis 28(4): 493-501.

33. den Dulk M, Collette L, van de Velde CJ, Marijnen CA, Calais G, et al. (2007) Quality of surgery in T3-4 rectal cancer: Involvement of circumferential resection margin not influenced by preoperative treatment. Results from EORTC trial 22921. Eur J Cancer 43(12): 1821-1828.

34. Chiappa A, Biffi R, Bertani E, Zbar AP, Pace U, et al. (2006) Surgical outcomes after total mesorectal excision for rectal cancer. J Surg Oncol 94(3): 182-193.

35. Laurent C, Leblanc F, Wütrich P, Scheffler M, Rullier E (2009) Laparoscopic versus open surgery for rectal cancer: Long-term oncologic results. Ann Surg 250(1): 54-61.

36. Jayne DG, Thorpe HC, Copeland J, Quirke P, Brown JM, et al. (2010) Five-year follow-up of the medical research council CLASICC trial of laparoscopically assisted versus open surgery for colorectal cancer. $\mathrm{Br}$ J Surg 97(11): 1638-1645.

37. Reza MM, Blasco JA, Andradas E, Cantero R, Mayol J (2006) Systematic review of laparoscopic versus open surgery for colorectal cancer. Br J Surg 93(8): 921-998.

38. Lujan J, Valero G, Hernandez Q, Sanchez A, Frutos MD, et al. (2009) Randomized clinical trial comparing laparoscopic and open surgery in patients with rectal cancer. Br J Surg 96(9): 982-989.

39. Law WL, Chu KW (2004) Abdominoperineal resection is associated with poor oncological outcome. Br J Surg 91(11): 1493-1499.

40. Nymann T, Jess P, Christiansen J (1995) Rate and treatment of pelvic recurrence after abdominoperineal resection and low anterior resection for rectal cancer. Dis Colon Rectum 38(8): 799-802.

41. Nakagoe T, Ishikawa H, Sawai T, Tsuji T, Tanaka K, et al. (2004) Survival and recurrence after a sphincter-saving resection and abdominoperineal 
resection for adenocarcinoma of the rectum at or 21 below the peritoneal reflection: A multivariate analysis. Surg Today 34(1): 32-39.

42. Ptok H, Marusch F, Kuhn R, Gastinger I, Lippert H (2007) Influence of hospital volume on the frequency of abdominoperineal resections and long-term oncological outcomes in low rectal cancer. Eur J Surg Oncol 33(7): 854-861.

43. Weiser MR, Quah HM, Shia J, Guillem JG, Paty PB, et al. (2009) Sphincter preservation in low rectal cancer is facilitated by preoperative chemoradiation and intersphincteric dissection. Ann Surg 249(2): 236242.

44. Reshef A, Lavery I, Kiran RP (2012) Factors associated with oncologic outcomes after abdominoperineal resection compared with restorative resection for low rectal cancer: Patient- and tumor-related or technical factors only? Dis Colon Rectum 55(1): 51-58.

45. Digennaro R, Tondo M, Cuccia F, Giannini I, Pezzolla F, et al. (2013) Coloanal anastomosis or abdominoperineal resection for very low rectal cancer: What will benefit, the surgeon's pride or the patient's quality of life? Int J Colorectal Dis 28(7): 949-957.

46. Ziv Y, Zbar A, Shavit BY, Igov I (2013) Low Anterior Resection Syndrome (LARS): Cause and effect and reconstructive considerations. Tech Coloproctol 17(2): 151-162.

47. Ridolfi TJ, Berger N, Ludwig KA (2016) Low anterior resection syndrome: Current management and future directions. Clin Colon Rectal Surg 29(3): 239-245

48. How P, Stelzner S, Branagan G, Bundy K, Chandrakumaran K, et al. (2012) Comparative quality of life in patients following abdominoperinea excision and low anterior resection for low rectal cancer. Dis Colon Rectum 55(4): 400-406.

49. Dumont F, Ayadi M, Goere D, Honore C, Elias D (2013) Comparison of fecal continence and quality of life between intersphincteric resection and abdominoperineal resection plus perineal colostomy for ultra-low rectal cancer. J Surg Oncol 108(4): 225-229.

50. Grumann MM, Noack EM, Hoffmann IA, Schlag PM (2001) Comparison of quality of life in patients undergoing abdominoperineal extirpation or anterior resection for rectal cancer. Ann Surg 233(2): 149-156.

51. Pachler J, Wille-Jørgensen P (2012) Quality of life after rectal resection for cancer, with or without permanent colostomy. Cochrane Database Syst Rev 12: CD004323.

52. Varpe P, Huhtinen H, Rantala A, Salminen P, Rautava P, et al. (2011) Quality of life after surgery for rectal cancer with special reference to pelvic floor dysfunction. Color Dis 13(4): 399-405.

53. Celasin H, Karakoyun R, Yilmaz S, Elhan AH, Erkek B, et al. (2011) Quality of life measures in Islamic rectal carcinoma patients receiving counselling. Color Dis 13(7): e170-e175.

\section{ISSN: 2574-1241}

\section{DOI: 10.26717/BJSTR.2019.20.003516}

Mehmer İlker Turan. Biomed J Sci \& Tech Res

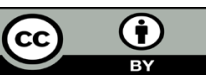

This work is licensed under Creative Commons Attribution 4.0 License

Submission Link: https://biomedres.us/submit-manuscript.php
54. Brennan CJ, Steele RJ (2002) Objective assessment of morbidity and quality of life after surgery for low rectal cancer. Color Dis 4(1): 61-66.

55. Thong MS, Mols F, Lemmens VE, Rutten HJ, Roukema JA, et al. (2011) Impact of preoperative radiotherapy on general and disease-specific health status of rectal cancer survivors: A population-based study. Int J Radiat Oncol Biol Phys 81(3): e49-58.

56. Krouse RS, Herrinton LJ, Grant M, Wendel CS, Green SB, et al. (2009) Health-related quality of life among long-term rectal cancer survivors with an ostomy: Manifestations by sex. J Clin Oncol 27(28): 4664-4670.

57. Fucini C, Gattai R, Urena C, Bandettini L, Elbetti C (2008) Quality of life among five-year 23 survivors after treatment for very low rectal cancer with or without a permanent abdominal stoma. Ann Surg Oncol 15(4): 1099-1106.

58. Kasparek MS, Hassan I, Cima RR, Larson DR, Gullerud RE, et al. (2011) Quality of life after coloanal anastomosis and abdominoperineal resection for distal rectal cancers: Sphincter preservation vs quality of life. Color Dis 13(8): 872-877.

59. Konanz J, Herrle F, Weiss C, Post S, Kienle P (2013) Quality of life of patients after low anterior, intersphincteric, and abdominoperineal resection for rectal cancer-A matched-pair analysis. Int J Colorectal Dis 28(5): 679-688.

60. Fischer A, Tarantino I, Warschkow R, Lange J, Zerz A, et al. (2010) Is sphincter preservation reasonable in all patients with rectal cancer? Int J Colorectal Dis 25(4): 425-432.

61. Maslyankov S, Penchev D, Todorov G, Vladov N (2015) A meta-analysis of quality of life, Estimated by questionnaires of the European Organization for Research and Treatment of Cancer (EORTC) after rectal cancer surgery. Chir 110(4): 356-361.

62. Demiral Y, Ergor G, Unal B, Semin S, Akvardar Y, et al. (2006) Normative data and discriminative properties of Short Form 36 (SF-36) in Turkish urban population. BMC Public Health 6: 247.

63. Park EJ, Cho MS, Baek SJ, Hur H, Min BS, et al. (2015) Long-term oncologic outcomes of robotic low anterior resection for rectal cancer. Ann Surg 261(1): 129-137.

64. Kwak JM, Kim SH (2016) Robotic surgery for rectal cancer: An update in 2015. Cancer Res Treat 48(2): 427-435.

65. Popescu I, Vasilescu C, Tomulescu V, Vasile S, Sgarbura O (2010) The minimally invasive approach, laparoscopic and robotic, in rectal resection for cancer: A single center 24 experience. Acta Chir Iugosl 57(3): 29-35.

66. Xiong B, Ma L, Huang W, Zhao Q Cheng Y, et al. (2015) Robotic versus laparoscopic total mesorectal excision for rectal cancer: a meta-analysis of eight studies. J Gastrointest Surg 19(3): 516-526.

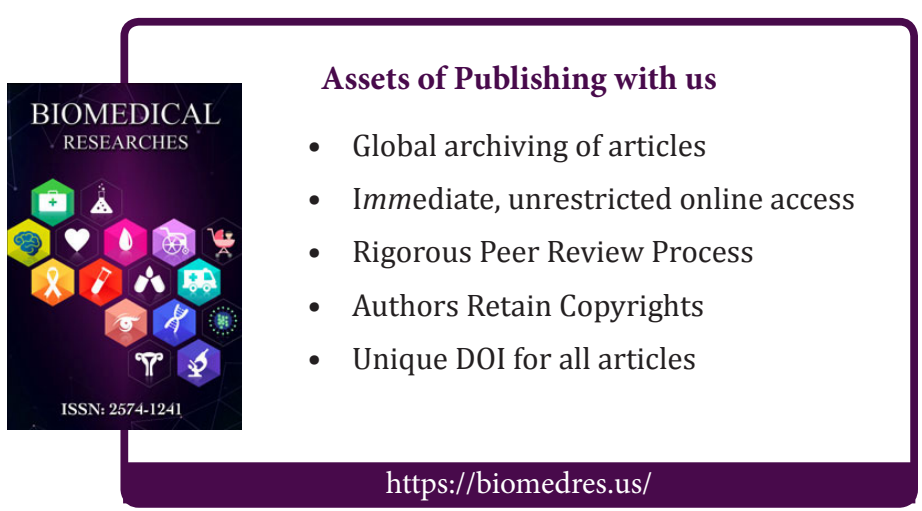

